\title{
Electroformation of quasi-two-dimensional silver patterns in the absence of supporting electrolyte
}

Received: 14 November 2002/ Accepted: 30 January 2003/Published online: 2 April 2003

(C) Springer-Verlag 2003

\begin{abstract}
Quasi-two-dimensional (2D) growth patterns of silver electrodeposits obtained from aqueous silver sulfate solution in the absence of supporting electrolyte using a quasi-2D cylindrical cell involve domains with morphologies covering from dense to needle-like branching. The prevailing morphology depends on the electrolyte concentration, applied electric potential and electrolysis time. From the time dependence of the maximum radius circumscribing each electrodeposit, its dimension was obtained. The growth of the solid phase was also analysed in terms of dimensionless numbers to estimate the ionic mass-transfer contributions to the electrochemical process. For a single-growing branch the axial-to-radial growth velocity is close to $10^{2}$. Phenomena promoting silver electrodeposits with irregular edges and an open structure compete with others operating in the opposite direction. These phenomena are influenced by changes in the concentration and electric potential field around the growing electrodeposit.
\end{abstract}

Keywords Electrodeposits $\cdot$ Silver $\cdot$ Two-dimensional growth

\section{Introduction}

The growth mode of a new solid phase formation depends on the environment, the nature of the substrate including

Dedicated to Prof. Dr. Wolf Vielstich on the occasion of his 80th birthday in recognition of his numerous contributions to interfacial electrochemistry

P. L. Schilardi · S. L. Marchiano · R. C. Salvarezza

A. J. Arvia (ه)

Instituto de Investigaciones Fisicoquímicas Teóricas y Aplicadas

(INIFTA), Universidad Nacional de La Plata - CONICET,

Sucursal 4, Casilla de Correo 16, 1900 La Plata, Argentina

E-mail: ajarvia@inifta.unlp.edu.ar its crystallographic orientation and topography, the temperature, the hydrodynamic conditions and the presence of external fields. The growth mode of the deposit is characterized by its apparent specific gravity and mechanical and surface properties. Random irregularities produced at the growing solid surface by an electric and/ or a concentration field promote local fluctuations favouring the appearance of transitions in the growth mode $[1,2,3]$.

Several procedures have been described for the preparation of solid branched aggregates. Among them, electrochemical procedures make it possible to control the quality of metal electrodeposits by handling operating variables over a wide range using either quasi-twodimensional (2D) $[4,5,6,7,8,9,10,11]$ or threedimensional (3D) electrochemical cells [12, 13, 14, 15]. Thus, under different conditions, zinc and copper electrodeposits yielding needle-like $[7,8,9,16,17,18]$, dendrite [6, 7], diffusion-limited aggregation-like patterns (DLA) $[5,6,7,9,10]$ and a densely branched growth mode (DBM) $[6,7]$ have been observed.

The formation of branched metal aggregates constitutes an issue of importance from both the fundamental standpoint and their applications. Kinetic data on branched aggregates become interesting to test the validity of and to improve existing growth models. However, the direct comparison of modelling to experimental data and vice versa is often limited by inherent difficulties in the interpretation and poor reproducibility of experiments $[4,5,6,7,8,9,10,12,13,14,15,16,17,18]$. On the other hand, branched aggregates are promising microstructural materials with special mechanical properties, although they have deleterious influence on hydrometallurgy and electroplating, causing short circuits in the electrochemical cells and poor quality electrodeposits.

This work describes the growth mode of silver electrodeposition that starts on a platinum cathode from silver sulfate-containing aqueous solutions, in the absence of supporting electrolyte, using quasi-2D electrochemical cells. The influence of silver salt concentration 
in the solution $\left(c_{0}\right)$, the potential at the cathode $\left(\Delta E_{\mathrm{c}}\right)$, the contribution of different mass transport processes and current distribution at different characteristic lengths and growth modes are considered. Pattern morphologies covering from dense to open branching, including dendrites and needle-like formations, can be observed. Rate controlling processes are discussed in terms of dimensionless numbers and current distribution effects.

\section{Experimental}

Most of the experiments were run with a quasi-2D cell made of two parallel glass plates and a concentric electrode arrangement consisting of a cathode, made from a piece of platinum wire $\left(99.99 \%\right.$, radius, $\left.r_{0}=0.035 \mathrm{~cm}\right)$, and a silver ring anode (radius, $r_{\mathrm{a}}=5.00 \mathrm{~cm}$, and thickness, $\left.l=0.02 \mathrm{~cm}\right)($ Fig. 1a). The thickness of the cell was in the range $0.03 \mathrm{~cm} \leq h \leq 0.05 \mathrm{~cm}$. A silver wire immersed in the same solution, connected to the cell through a capillary tip located at the upper glass plate, was used as the reference electrode. The cell design assured, at least initially, a homogeneous primary current distribution. The cell was placed on a horizontally suspended table to avoid mechanical vibrations [11].

Working solutions consisted of aqueous silver sulfate $\left(10^{-3} \mathrm{M} \leq c_{0} \leq 2.4 \times 10^{-2} \mathrm{M}\right)$, prepared from Milli-Q* water and analytical reagent-grade chemicals. Prior to filling the electrochemical cell, solutions were saturated with purified nitrogen for

(a)

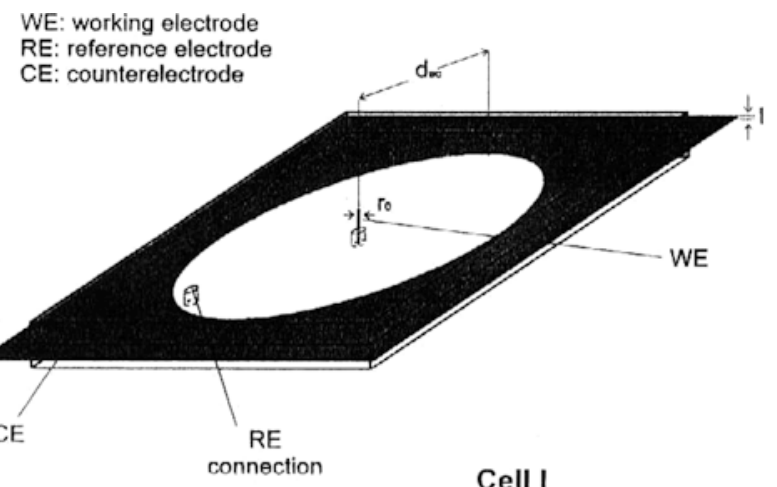

(b)

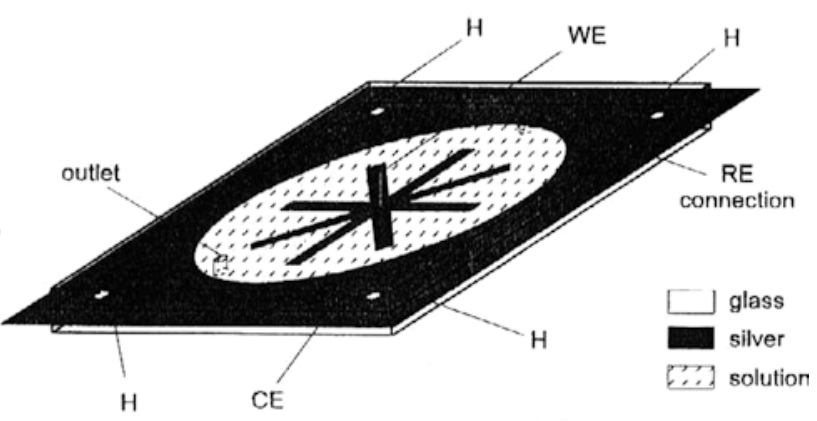

Cell II

Fig. 1 (a) Scheme of the quasi-2D cylindrical cell (cell I) used for the electrodeposition of silver. WE $=$ working electrode; $\mathrm{CE}=$ counter electrode; $\mathrm{RE}=$ reference electrode. (b) Scheme of the quasi-2D cylindrical cell (cell II) used for the determination of the Ohmic resistance with a central "star-like" electrode. $\mathrm{H}=$ holding clamp sites
$2 \mathrm{~h}$. The cathode-to-anode and the cathode-reference-electrode ohmic drops were determined by conventional conductometry.

Polarization curves were recorded at potential scan rates $(v)$ in the range $0.001 \leq v \leq 0.100 \mathrm{~V} / \mathrm{s}$. Silver aggregates were grown in the range $0.38 \mathrm{~V} \leq \Delta E_{\mathrm{c}} \leq 0.80 \mathrm{~V}$, keeping the cathodic polarization $\left(\Delta E_{\mathrm{c}}\right)$ constant with respect to the reference electrode.

For each growing electrodeposit, a sequence of photographs at a different time $(t)$ was taken, and simultaneously the cathodic current $(I)$ and the cathodic charge $(Q)$ transients were recorded. Two main sets of transients were obtained. In one of them (data set A), $\Delta E_{\mathrm{c}}=0.68 \mathrm{~V}$ and $c_{0}$ was changed as mentioned above; in another (data set $\mathrm{B}$ ), $c_{0}=2.4 \times 10^{-2} \mathrm{M}$ and $\Delta E_{\mathrm{c}}$ varied as already indicated. For both sets $\mathrm{A}$ and $\mathrm{B}$, repetitive runs were made to establish the reproducibility of data. Further morphological details of the silver electrodeposits were obtained from scanning electron micrographs.

\section{Results}

\section{Polarization curves}

A typical polarization curve of silver electrodeposition recorded at $v=0.05 \mathrm{~V} / \mathrm{s}$ starting from a platinum cathode is shown in Fig. 2. In a cell with a radially growing cathode the current seldom attains a constant value because the cathodic surface area $(S)$ varies continuously with the electrolysis time $(t)$ [19]. This situation turns out to be more complicated when branched electrodeposits are formed.

The first part of theses curves tends to reach an ionic mass-transfer-limited current over a potential range that decreases with $v$. Beyond this potential range, an increase in current with $\Delta \mathrm{E}_{\mathrm{c}}$ due to the increase in $S$ can be seen.

For recording current and charge transients the values of $\Delta \mathrm{E}_{\mathrm{c}}$ were chosen from polarization curves, considering the range of potential where the electrochemical

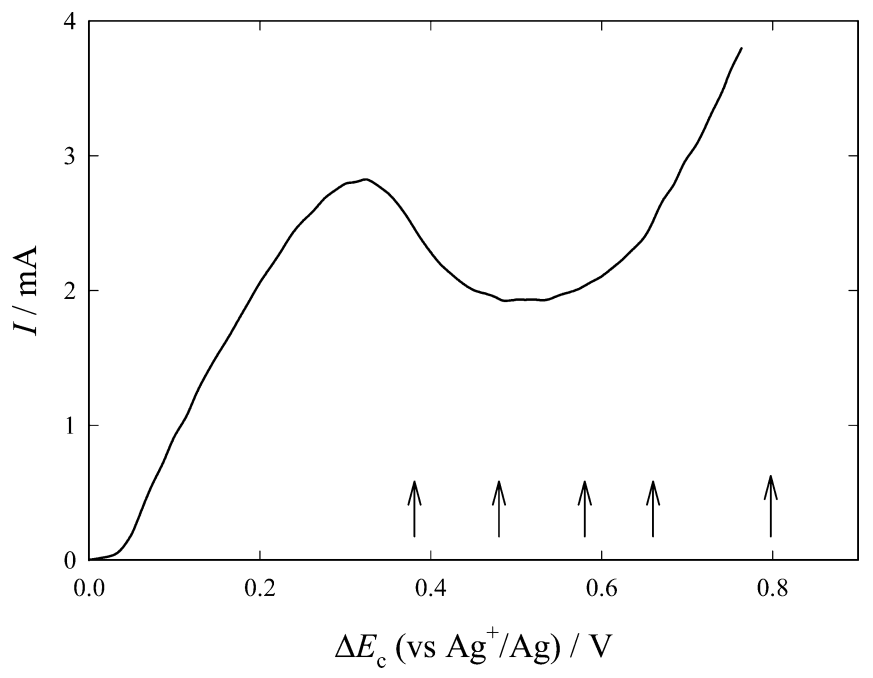

Fig. 2 Typical polarization curve for the electrodeposition of silver on platinum from aqueous $0.024 \mathrm{M}$ silver sulfate using cell $\mathrm{I}$. $S=0.223 \mathrm{~cm}^{2} ; v=0.05 \mathrm{~V} / \mathrm{s} ; 298 \mathrm{~K}$. Arrows indicate the values of $\Delta \mathrm{E}_{\mathrm{c}}$ used in this work 
reaction is under ionic mass-transfer rate control (Fig. 2).

\section{Determination of cell resistance}

Owing to the relatively large cathode-to-anode distance $\left(d_{\mathrm{ac}}\right)$ and the small height $(h)$ of the cell without a supporting electrolyte (small specific conductivity), the ohmic resistance $\left(R_{\Omega}\right)$ is large. Therefore, it was necessary to determine its value in order to evaluate the ohmic overpotential $\left(\eta_{\Omega}\right)$. The value of $\mathrm{R}_{\Omega}$ was determined by conductometry and calculated from Ohm's law for a concentrically electrode arrangement:

$R_{\Omega}=(2 \pi h \kappa)^{-1} \ln \left(r_{\mathrm{a}} / r_{\mathrm{w}}\right)$

where $r_{\mathrm{a}}$ is the inner radius of the ring anode, $r_{\mathrm{w}}$ is the radius of the cylindrical working electrode and $\kappa$ is the specific conductivity of the solution (Fig. 3). For $t=0$, $r_{\mathrm{W}}=r_{0}$.

For irregular electrodeposits, the validity of Eq. 1 was verified using mummy cells provided with starshaped cathodes (Fig. 2b). These electrodes could approximately be described as cylinders of $h=0.05 \mathrm{~cm}$ and radius equal to that of the smallest circumference circumscribing the working electrode. Likewise, values of $R_{\Omega}$ from the cell with silver branched cathodes of different size and shape were also determined (Fig. 3). In this case, for $r_{\mathrm{m}}<1.5 \mathrm{~cm}, r_{\mathrm{m}}$ being the greatest outer radius of the electrodeposit, the agreement between experimental data and Eq. 1 was reasonably good.

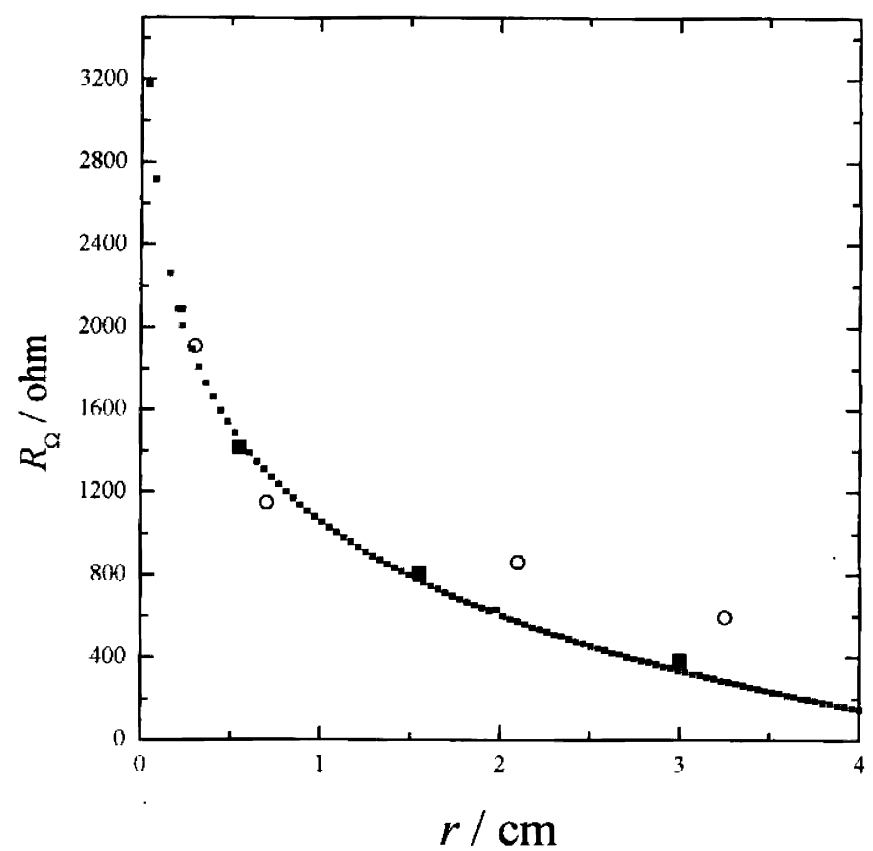

Fig. $3 \mathrm{Ohmic}$ resistance $\left(R_{\Omega}\right)$ versus $r_{\mathrm{m}}$ plot. Open circles: data from different electrodeposits as described in the text. Large squares: data from cell II. Small squares: data from Eq. 1 for $c_{0}=2.4 \times 10^{-2} \mathrm{M}$ and $\kappa=4.83 \times 10^{-3} \Omega^{-1} \mathrm{~cm}^{-1}$ at $298 \mathrm{~K}$, and $h=$ $0.05 \mathrm{~cm}$
Conversely, for $r_{\mathrm{m}}>1.5 \mathrm{~cm}$, the irregularity of the electrodeposits becomes sufficiently large so that experimental values of $R_{\Omega}$ exceed the predictions of Eq. 1 . These results show that the true value of $\eta_{\Omega}$ depends on the size and shape of the silver electrodeposits.

\section{Morphology of silver electrodeposits}

Silver electrodeposition on platinum at potentials far from equilibrium involves first a nucleation and growth of a thin compact layer [15]. Afterwards, as $t$ and the size of the electrodeposit increase, the development of different types of branching, depending on $c_{0}, \Delta E_{\mathrm{c}}$ and $t$, can be seen (Figs. 4 and 5). Generally, these branched patterns can be described as either dense (type I), open (type II), dendrite (type III) or needle-like (type IV). Branching of types I and II shows tip splitting.

Photographs of silver electrodeposits resulting from data set $\mathrm{A}$ for $\Delta \mathrm{E}_{\mathrm{c}}=0.68 \mathrm{~V}$ and variable $c_{0}$ (Fig. $\left.4 \mathrm{a}, \mathrm{b}\right)$ show that the type of branching depends on $c_{0}$ and $t$. For $c_{0}=2.5 \times 10^{-3} \mathrm{M}$ (Fig. 4a), branching of types I and III dominates the growth pattern. For $c_{0} \geq 1.4 \times 10^{-2} \mathrm{M}$ (Fig. 4b), the patterns show branching of types II and III with a small lateral secondary branching.

Photographs of silver electrodeposits resulting from data set $\mathrm{B}$ for $c_{0}=2.4 \times 10^{-2} \mathrm{M}$ and variable $\Delta \mathrm{E}_{\mathrm{c}}$

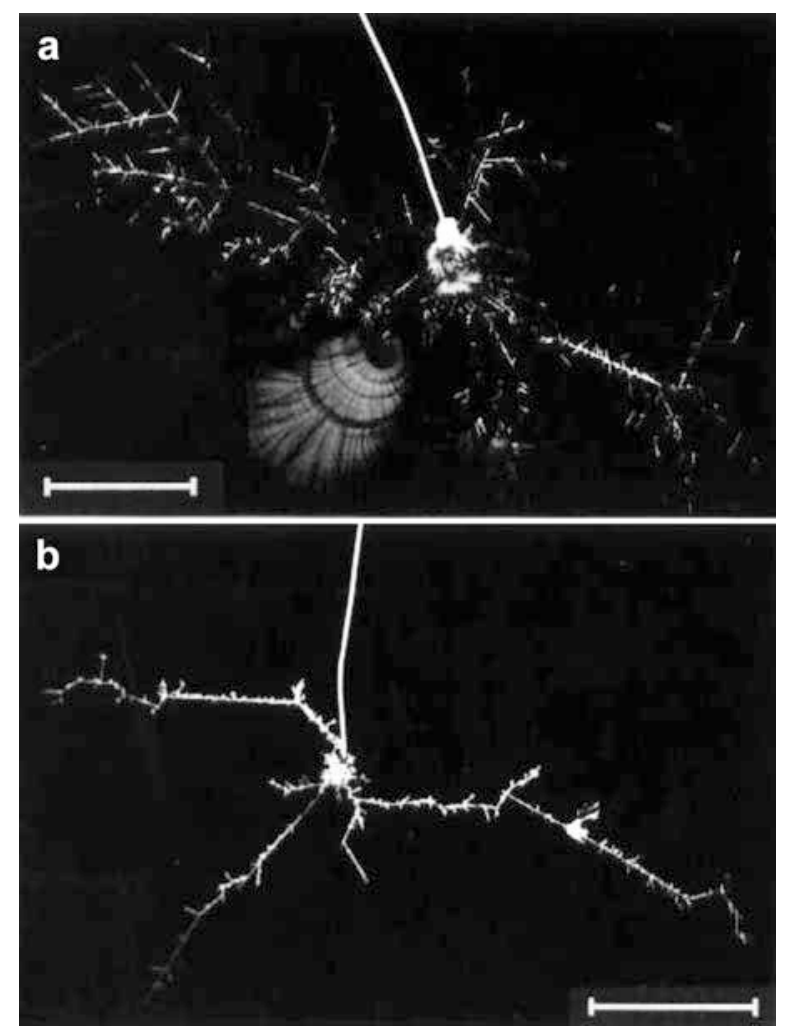

Fig. 4 Photographs showing the influence of $c_{0}$ on the shape of the silver electrodeposits from aqueous silver sulfate grown at $\Delta E_{\mathrm{c}}=0.680 \mathrm{~V}$ : (a) $c_{0}=2.5 \times 10^{-3} \mathrm{M}$; (b) $c_{0}=2.4 \times 10^{-2} \mathrm{M} ; 298 \mathrm{~K}$; reference bar $1 \mathrm{~cm}$ 
Fig. 5 Photographs of silver electrodeposits produced from aqueous $0.024 \mathrm{M}$ silver sulfate: (a) $\Delta E_{\mathrm{c}}=0.38 \mathrm{~V}$; (b) $\Delta E_{\mathrm{c}}=0.48 \mathrm{~V} ;(\mathrm{c}) \Delta E_{\mathrm{c}}=0.58 \mathrm{~V}$ $\Delta E_{\mathrm{c}}=0.80 \mathrm{~V} ; 298 \mathrm{~K} ;$ reference bar $1 \mathrm{~cm}$ (d) $\Delta E_{\mathrm{c}}=0.68 \mathrm{~V} ;(\mathrm{e})$
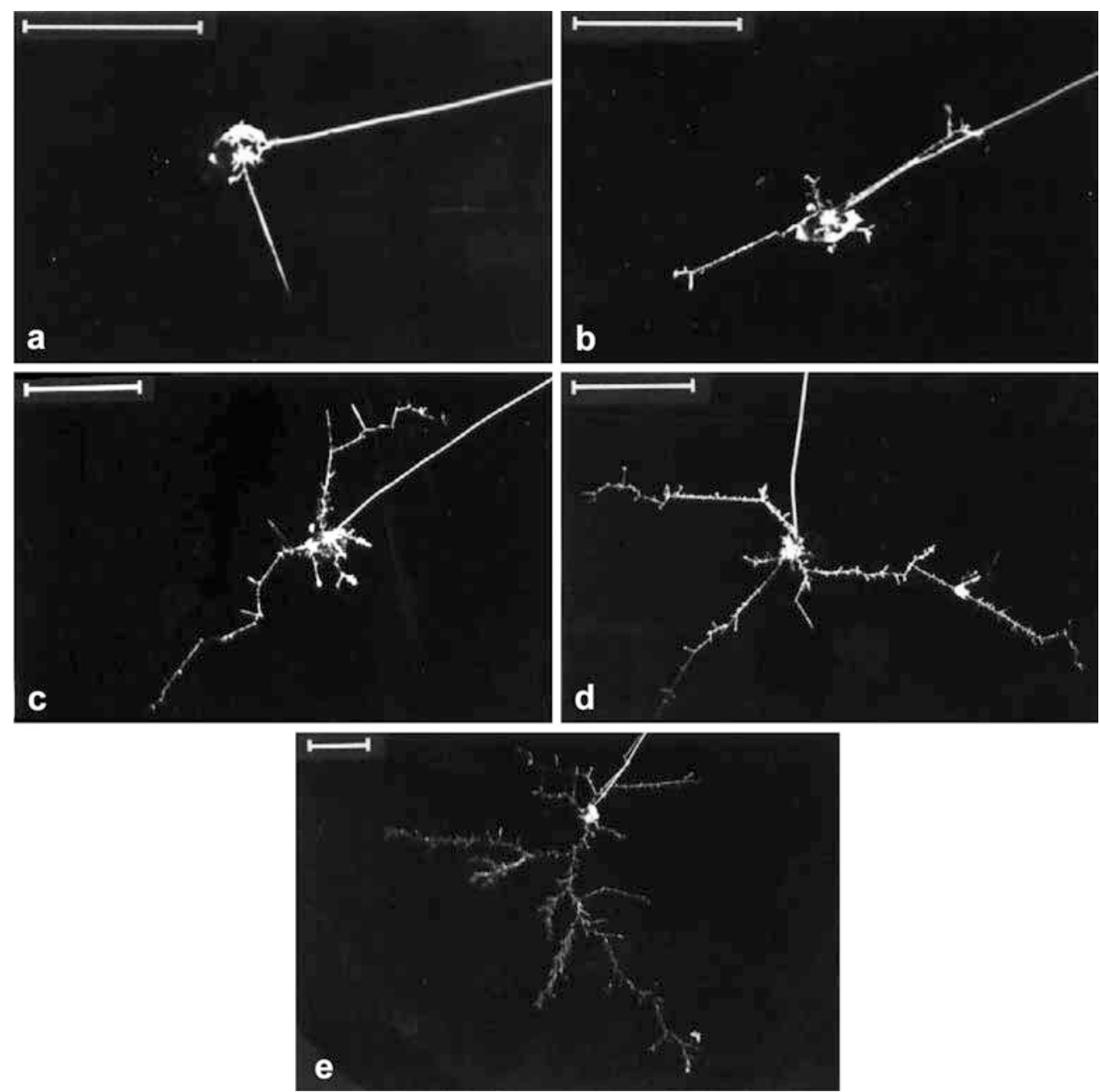

(Fig. 5a-e) also show different types of branching that depend on $\Delta \mathrm{E}_{\mathrm{c}}$ and $t$. For $\Delta E_{\mathrm{c}}=0.38 \mathrm{~V}$, branching starts on certain sites of the thin compact deposit initially formed. At this potential a single needle tends to dominate the growth pattern (Fig. 5a). For $\Delta E_{\mathrm{c}}=0.48 \mathrm{~V}$ (Fig. 5b), thick and large branches of type III decorated by a small branching are produced. The number of zigzag-decorated silver branches tends to increase with $\Delta E_{\mathrm{c}}$ (Fig. $5 \mathrm{c}, \mathrm{d}$ ). In this case, most segments of large branches tend to form $30^{\circ}$ multiple angles. For $\Delta E_{\mathrm{c}}=0.80 \mathrm{~V}$, open branching (type II) tends to dominate the growth pattern (Fig. 5e). These patterns also confirm that some branches grow continuously, while the tips of others become thicker and their longitudinal growth rate practically decreases to zero (Fig. 6).

\section{Current transients}

In general, most current transients (Fig. 7), which are related to the formation of silver electrodeposits depicted in Figs. 4 and 5, exhibit a complex functionality that correlates with the shape evolution of the electrodeposits in terms of size $\left(r_{\mathrm{m}}\right)$ and morphology. For $r_{\mathrm{m}}>r_{0}$, both $I$ and $r_{\mathrm{m}}$ increase continuously as branching is produced. The slope $\Delta I / \Delta t$ depends on the type of branching, i.e. on the density number of branches and branching growth-rate distribution. Only for a single needle the slope $\Delta I / \Delta t$ remains almost constant. In all cases, branching appears at random at different electrodeposit surface sites either at early stages $(t \rightarrow 0)$ or after a certain time that depends on $\Delta \mathrm{E}_{\mathrm{c}}$ and $c_{0}$.

\section{Dimension of branched electrodeposits}

As $c_{0}$ is increased, growth patterns (data set A, Fig. 4) tend to change from dense to open branching. Otherwise, as $\Delta \mathrm{E}_{\mathrm{c}}$ is increased, growth patterns (data set $\mathrm{B}$, Fig. 5) tend to change from needle-like to open branching and dendrites.

The geometry characterization of global electrodeposits (either data set A or B) was made from the following relationship $[1,2,3]$ :

$Q \propto r_{\mathrm{m}}^{D_{\mathrm{M}}}$

Then the dimension $\left(D_{\mathrm{M}}\right)$ resulting from the $\log Q$ versus $\log r_{\mathrm{m}}$ plot is $D_{\mathrm{M}} \approx 1.6$, i.e. a fractal dimension $\left(D_{\mathrm{F}}\right)$, for the range $10^{-3} \mathrm{M} \leq c_{0} \leq 2.4 \times 10^{-2} \mathrm{M}$ (Fig. 8a). Similarly, for constant $c_{0}, D_{\mathrm{M}}=1.7 \pm 0.1$ for the range $0.48 \mathrm{~V} \leq$ 


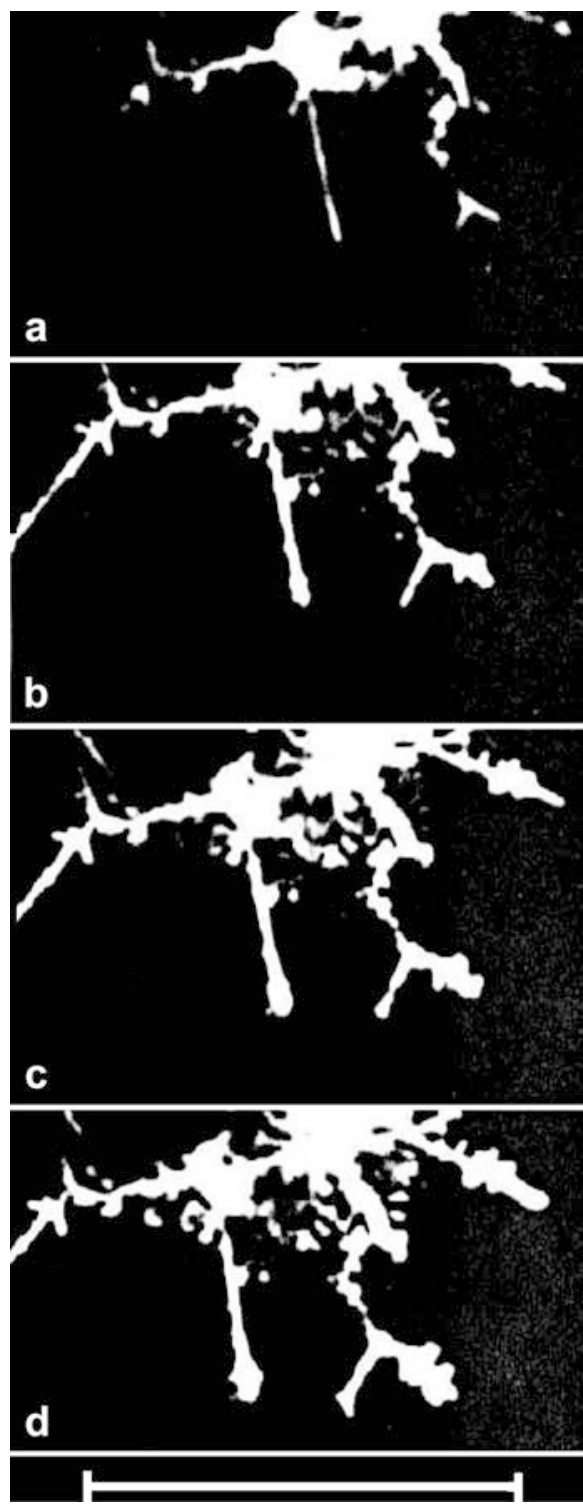

Fig. 6 Sequential photographs of a branched electrodeposit grown from $0.024 \mathrm{M}$ aqueous silver sulfate at $\Delta E_{\mathrm{c}}=0.58 \mathrm{~V}$ : (a) $t=2400 \mathrm{~s}$, $Q=0.60 \mathrm{C}$; (b) $t=6960 \mathrm{~s}, Q=2.28 \mathrm{C}$; (c) $t=12,360 \mathrm{~s}, Q=4.67 \mathrm{C}$; (d) $t=21,480 \mathrm{~s}, Q=9.31 \mathrm{C}$; reference bar $1 \mathrm{~cm}$

$\Delta E_{\mathrm{c}} \leq 0.68 \mathrm{~V}$ (Fig. $8 \mathrm{~b}$ ). This value of $D_{\mathrm{M}}$ is close to the fractal dimension that has been derived from a DLA growth model and dendritic patterns $\left(D_{\mathrm{F}} \rightarrow 1.71\right)[1,2$, 3]. On the other hand, a single needle tip resulting in $\Delta E_{\mathrm{c}}=0.38 \mathrm{~V}$ and low $c_{0}$ (Fig. 5a) behaves as an object with an Euclidean dimension $\left(D_{\mathrm{E}}\right)$, i.e. $D_{\mathrm{M}}=D_{\mathrm{E}}=1$.

The values of $D_{\mathrm{M}}$ were obtained from 35 sets of data resulting from growth patterns of experiments repeated at least twice.

\section{Directional growth rates of branched electrodeposits}

The average longitudinal $\left(v_{\mathrm{r}}\right)$ and transversal $\left(v_{\mathrm{w}}\right)$ growth velocities of each branch were determined. From growth
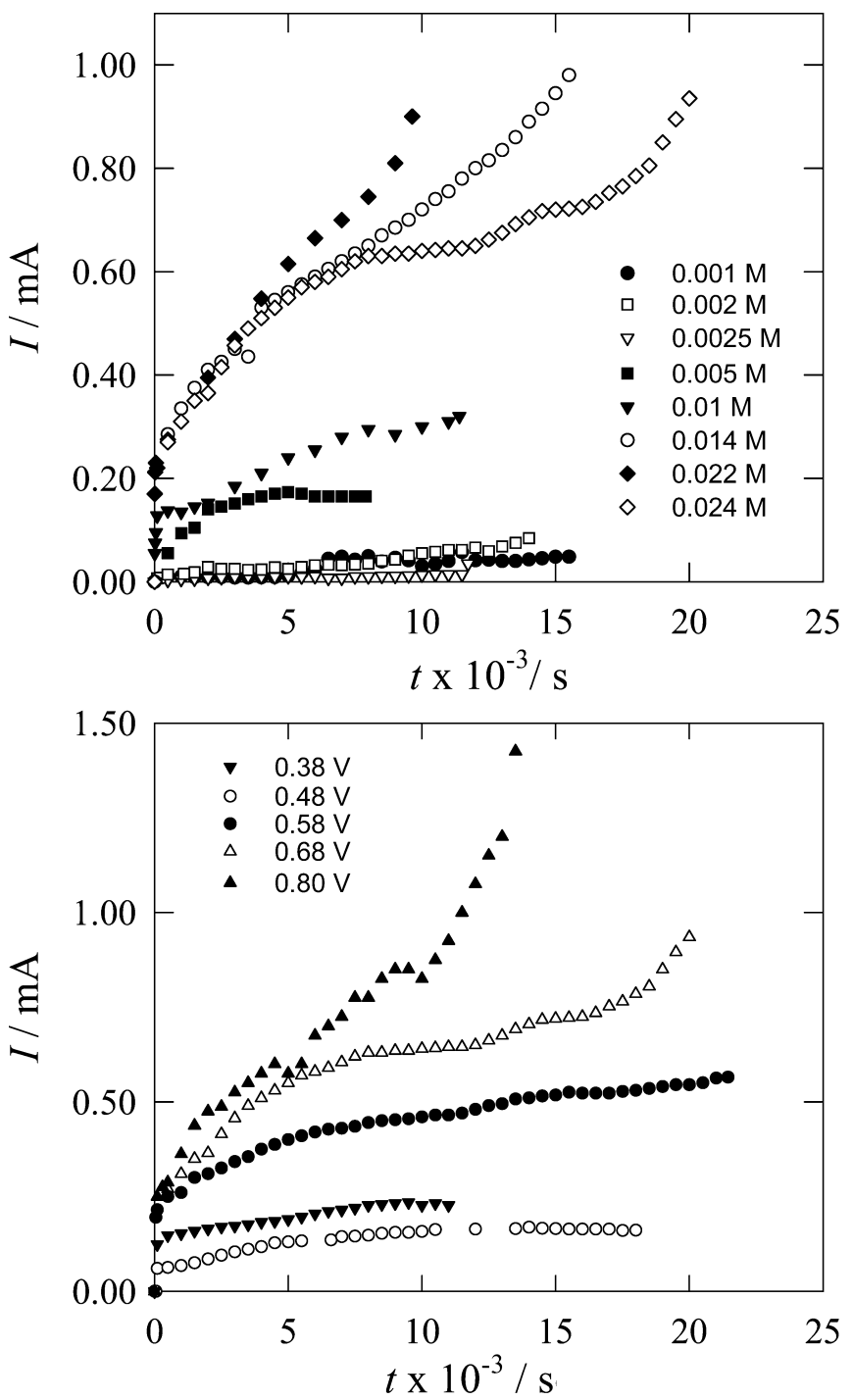

Fig. 7 Current transients for silver electrodeposition from aqueous silver sulfate at $298 \mathrm{~K}$ : (a) $\Delta E_{\mathrm{c}}=0.68 \mathrm{~V}$; (b) $c_{0}=0.024 \mathrm{M}$

patterns produced at $c_{0}=2.4 \times 10^{-2} \mathrm{M}$ and $\Delta E_{\mathrm{c}}=0.38 \mathrm{~V}$, the needle-like branch consists of a ca. $0.2 \mathrm{~mm}$ diameter rod-like stem with a sharp tip (Fig. 5a). It appears that out of the various small nodules that can be seen at the stem basis, only the tip with the smallest radius of curvature $\left(r_{\mathrm{t}}\right)$ maintains its shape as its growing front continuously displaces. Conversely, branching centres at nodules can also be formed during growth.

Runs at $c_{0}=2.4 \times 10^{-2} \mathrm{M}$ and $\Delta E_{\mathrm{c}}=0.58 \mathrm{~V}$ (Fig. $6 \mathrm{a}-\mathrm{d}$ ) show that some branches, particularly those with a rather thick tip, become practically "dead" branches, although they continue to grow slowly to produce local compact domains.

Average data for $v_{\mathrm{r}}$ and $v_{\mathrm{w}}$ from a single branch, calculated from magnified patterns at different $\Delta E_{\mathrm{c}}, c_{0}$ and $t_{\mathrm{d}}$, are assembled in Table 1 . The number of hindered-growth branches increases with $c_{0}$ and decreases with $\Delta E_{\mathrm{c}}$. The $\left\langle v_{\mathrm{r}}\right\rangle /\left\langle v_{\mathrm{w}}\right\rangle$ ratio is in the order of $10^{2}$, 
irrespective of $c_{0}$ and $\Delta E_{\mathrm{c}}$. This figure is consistent with data derived for gold dendrite electroformation on highly oriented pyrolytic graphite [20].

\section{Discussion}

General considerations for silver electrodeposition from a binary electrolyte

Silver ion electrodeposition on silver from silver-ioncontaining aqueous solution can be represented by the following reversible reaction:
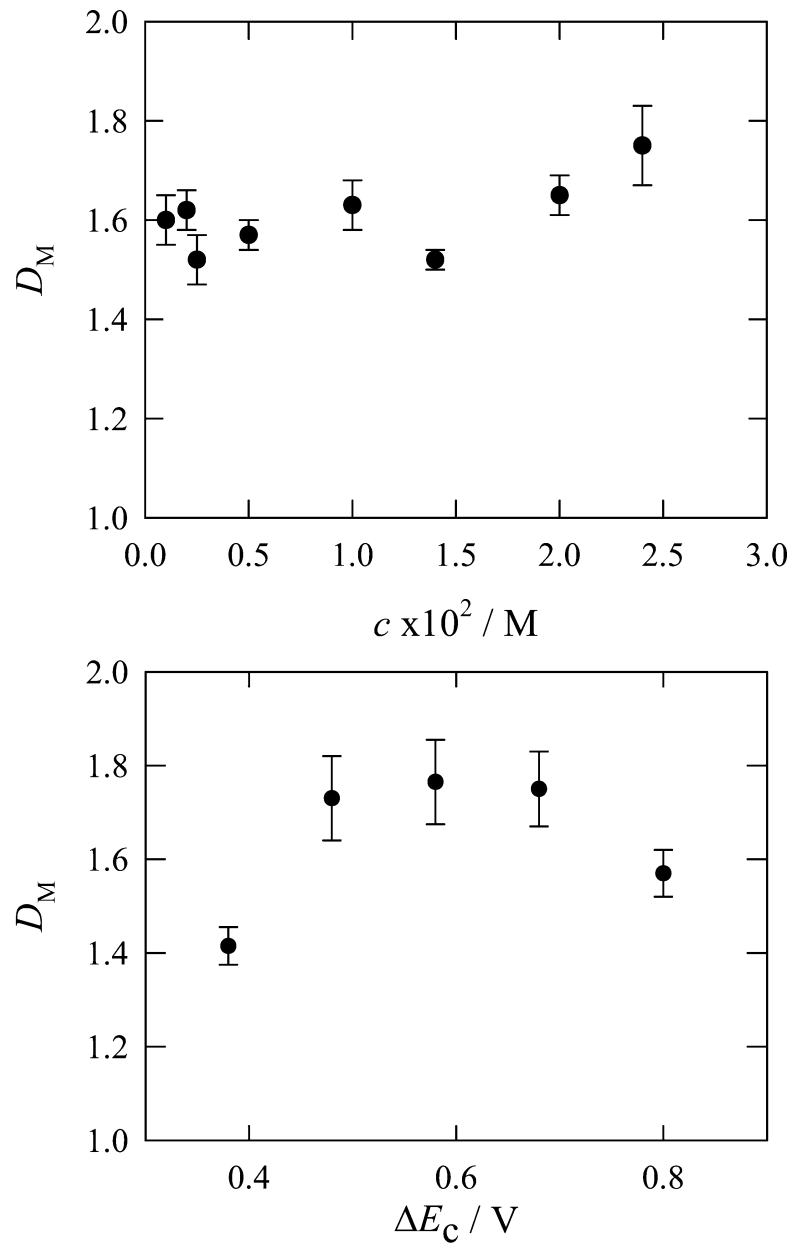

Fig. 8 (a) $D_{\mathrm{M}}$ versus $c_{0}$ plot; $\Delta E_{\mathrm{c}}=0.68 \mathrm{~V}$. (b) $D_{\mathrm{M}}$ versus $\Delta E_{\mathrm{c}}$ plot; $0.024 \mathrm{M}$ aqueous silver sulfate; $298 \mathrm{~K}$

$$
\begin{aligned}
\operatorname{Ag}^{+}(\mathrm{aq})+\mathrm{e}^{-}(\text {cathode }) \longrightarrow & \mathrm{Ag}^{+}(\text {crystal }) \\
& +\mathrm{e}^{-}(\text {conduction band })
\end{aligned}
$$

The equilibrium potential $\left(E_{\mathrm{r}}\right)$ of reaction (3) is given by the Nernst equation:

$E_{\mathrm{r}}($ Vvs.SHE, $298 \mathrm{~K})=0.799+0.059 \log \left(a_{\mathrm{i}} / a_{0}\right)$

where $a_{\mathrm{i}}$ and $a_{0}$ are the activity of silver ions in the solution and solid silver, respectively, the latter being taken equal to 1 .

The kinetics of reaction (3) is strongly dependent upon the crystallographic faces, their distribution and the existence of surface defects [21, 22, 23, 24, 25]. Thus, for stepped polycrystalline silver surfaces, the exchange current density at $298 \mathrm{~K}$ is $j_{0}=24 \pm 5 \mathrm{~A} / \mathrm{cm}^{2}$ for $c_{0}=1 \mathrm{M}$ [22]. Accordingly, on these electrode surfaces, reaction (3) can be considered as one of the fastest, most electrochemically reversible interfacial processes. Then, under conventional electrodeposition conditions such as those used in this work, the global kinetics of reaction (3) is under ionic mass-transfer rate control. Therefore, the steady flux of depositing ions (i) towards the electrode surface can be expressed by the convective diffusion equation $[26,27]$ :

$\mathbf{N}_{\mathbf{i}}=D_{\mathrm{i}} \nabla c_{\mathrm{i}}-\mathbf{V} c_{\mathrm{i}}+z_{\mathrm{i}} u_{\mathrm{i}} c_{\mathrm{i}} F \nabla \phi$

where $N_{\mathrm{i}}$ is the mass transfer flux vector for depositing i ions, $D_{\mathrm{i}}$, the corresponding diffusion coefficient, $\boldsymbol{V}$ the fluid velocity vector, $\phi$ the single electrode potential and $u_{\mathrm{i}}$ the i-ion mobility. Considering the electroneutrality condition and a simple cell geometry, the solution of Eq. 5 leads to a current density equation formally similar to that derived either in the presence of a supporting electrolyte or for a binary electrolyte provided that the solution diffusion coefficient $\left(D_{\mathrm{s}}\right)$ rather than the diffusion coefficient of each reacting ion $\left(D_{\mathrm{i}}\right)$ is used in the flux equation. The relationship between $D_{\mathrm{s}}$ and $D_{\mathrm{i}}$ is $[26,27]$ :

$D_{\mathrm{s}}=D_{-} D_{+}\left(z_{+}-z_{-}\right) /\left(z_{+} D_{+}-z_{-} D_{-}\right)$

where $z_{+}, z_{-}$and $D_{+}, D_{-}$denote the charge and the diffusion coefficient of cations (+) and anions (-), respectively.

Let us consider dimensionless numbers to estimate the different contributions to ionic mass-transfer-controlled silver electrodeposition [28, 29]. The Péclet
Table 1 Results from magnified silver ramified patterns for different values of $c_{0}$ and $\Delta E_{\mathrm{c}}$ at

\begin{tabular}{|c|c|c|c|c|c|c|}
\hline$\Delta E_{\mathrm{c}}(\mathrm{V})$ & $\begin{array}{l}\text { Range } \\
\text { of } t\left(10^{3} \mathrm{~s}\right)\end{array}$ & $\begin{array}{l}\text { Range } \\
\text { of } Q\left(\mathrm{C} / \mathrm{cm}^{2}\right)\end{array}$ & $\begin{array}{l}\text { Total number of } \\
\text { branches }\end{array}$ & $\begin{array}{l}\text { Number of "dead" } \\
\text { branches }\end{array}$ & $\begin{array}{l}<v_{\mathrm{r}}>\times 10^{4} \\
(\mathrm{~cm} / \mathrm{s})\end{array}$ & $\begin{array}{l}<v_{\mathrm{w}}>\times 10^{6} \\
(\mathrm{~cm} / \mathrm{s})\end{array}$ \\
\hline \multicolumn{7}{|c|}{$0.024 \mathrm{M} \mathrm{Ag}_{2} \mathrm{SO}_{4}$} \\
\hline 0.38 & $5.4-9.12$ & $0.92-1.74$ & 9 & 8 & $1.2 \pm 0.8$ & $3 \pm 1$ \\
\hline 0.58 & $2.4-21.5$ & $0.60-9.31$ & 8 & 3 & $0.8 \pm 0.2$ & $0.7 \pm 0.3$ \\
\hline 0.68 & $1.2-16.2$ & $0.34-9.64$ & 7 & 1 & $1.1 \pm 0.2$ & $0.7 \pm 0.4$ \\
\hline \multicolumn{7}{|c|}{$0.010 \mathrm{M} \mathrm{Ag}_{2} \mathrm{SO}_{4}$} \\
\hline 0.68 & $1.68-11.5$ & $0.21-2.59$ & 6 & 4 & $1.4 \pm 0.3$ & $2 \pm 1$ \\
\hline
\end{tabular}
$298 \mathrm{~K}$ 
number $(\mathrm{Pe})$ indicates whether the rate of displacement of the growing front becomes sufficiently high to produce forced convection, whereas the Rayleigh number (Ra) is an indication of the contribution of free convection. Pe results from the product of the Reynolds $(\mathrm{Re})$ and Schmidt $(\mathrm{Sc})$ numbers [26, 30]:

$\mathrm{Pe}=\mathrm{Re} \times \mathrm{Sc}=\delta_{\mathrm{h}} / \delta_{\mathrm{d}}=L v_{\mathrm{r}} / 2 D_{\mathrm{s}}$

where $\delta_{\mathrm{h}}$ and $\delta_{\mathrm{d}}$ are the thickness of the hydrodynamic and mass-transfer boundary layer, respectively, $L$ is the characteristic length of the system, and $v_{\mathrm{r}}$ is the displacement rate of the growth front. The Rayleigh ( $\mathrm{Ra})$ number is the product of the Grashof $(\mathrm{Gr})$ and Schmidt (Sc) numbers:

$\mathrm{Ra}=\mathrm{Gr} \times \mathrm{Sc}=g \alpha L^{3} / v D_{\mathrm{s}}$

where $g$ is the gravity constant, $v$ the cinematic viscosity of the solution and $\alpha$ the densification coefficient, defined as [26]:

$\alpha=\left(c_{0} / \rho_{0}\right)(\partial \rho / \partial c)$

where $\rho^{0}$ and $\rho$ are the specific gravity in the bulk of the solution and in the diffusion layer, respectively. The same subscripts are applied to the concentration terms.

Values of Pe and Ra calculated from Eqs. 7 and 8 for different growth patterns (Figs. 4 and 5) are assembled in Table 2, where data used for the calculations are also included. For isolated branch tips (Fig. 5a) we consider $L=r_{\mathrm{t}}$, the value of $r_{\mathrm{t}}$ being determined from SEM micrographs (Fig. 9), whereas for global branched patterns we considered either $L=r_{\mathrm{m}}$ or $L=h$. Data indicate that for the growth of both silver single tips and branched patterns the influence of forced convection can be disregarded. For isolated tips, $\mathrm{Ra}<31,32]$.

Contributions to the growth of branched patterns

The change in the shape of the deposit from cylindrical to irregularly branched along the process indicates that the initially axially symmetric current distribution changes to an arbitrarily non-uniform one due to the influence of local concentration fluctuations at the

Table 2 Dimensionless numbers calculated for single tips and ramified silver electrodeposits (aqueous $0.024 \mathrm{M}$ silver sulfate, $298 \mathrm{~K})^{\mathrm{a}}$

\begin{tabular}{lllll}
\hline Morphology type & $L(\mathrm{~cm})$ & $\left\langle v_{\mathrm{r}}\right\rangle(\mathrm{cm} / \mathrm{s})$ & Pe & $\mathrm{Ra}$ \\
\hline Tip & 0.004 & $6 \times 10^{-5}$ & $1.2 \times 10^{-2}$ & - \\
Tip & 0.01 & $2.3 \times 10^{-4}$ & $1.9 \times 10^{-2}$ & $9.8 \times 10^{-1}$ \\
Branching & 0.035 & $1 \times 10^{-4}$ & $1.75 \times 10^{-1}$ & - \\
Branching & 4 & $6 \times 10^{-4}$ & $1.20 \times 10^{2}$ & - \\
Branching & 0.03 & - & - & $2.7 \times 10^{1}$ \\
Branching & 0.05 & - & - & $1.25 \times 10^{2}$
\end{tabular}

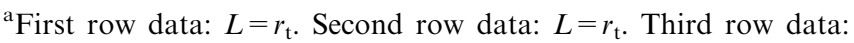
$L=r_{0}$. Fourth row data: $L=r_{\mathrm{m}}$. Fifth and sixth rows data: $L=h$. Values of $\alpha=0.01, v=0.01 \mathrm{~cm}^{2} / \mathrm{s}$ and $D_{\mathrm{s}}=1.2 \times 10^{-5} \mathrm{~cm}^{2} / \mathrm{s}$ at $298 \mathrm{~K}$ were taken from $[26,27,29]$ electrodeposit surface. Local concentration fluctuations trigger the growth of local irregularities as the nucleation of depositing atoms is involved in the electrocrystallization of metals. The formation of new nuclei requires a certain overpotential that is a part of the electrocrystallization overpotential, but once nuclei are formed the latter decreases and the current density on the newly formed small crystals increases. Subsequently, the attachment of depositing atoms onto the lattice occurs preferentially at step sites or protrusions where there is an increase in the average current density.

On the other hand, for an ionic mass-transfer-controlled process, such as silver electrodeposition on a platinum substrate, branching triggering occurs after a first compact silver thin layer is formed on the substrate [15]. Accordingly, as the number of irregularities begins to increase, a non-homogeneous current microdistribution profile sets in. Then, let us compare the value of $\delta_{\mathrm{d}}$ to the branch tip separation $\left(L^{\prime}\right)$. In fact, $\delta_{\mathrm{d}}$ varies from an initially uniform value around the cylindrical cathode $\left(L^{\prime}<\delta_{\mathrm{d}}\right)$ to different local values at the irregularly branched cathode, i.e. small and large values of $\delta_{\mathrm{d}}$ at protrusions and valleys, respectively. The average value of $\delta_{\mathrm{d}}$ estimated from the ratio $<\delta_{\mathrm{d}}>=D_{\mathrm{s}}$ $\left.<v_{\mathrm{r}}\right\rangle$ varies in the range $\left.0.025 \leq<\delta_{\mathrm{d}}\right\rangle \leq 0.20 \mathrm{~cm}$.

The dense morphology arising for $L>\delta_{\mathrm{d}}$ and $L^{\prime}<\delta_{\mathrm{d}}$ indicates that all surface sites approach a similar growing probability. In this case, the value of $\delta_{\mathrm{d}}$ tends to be independent of the microstructure of the deposit surface. Also in this case, free convection contributes to the transport process, as is concluded from the analysis of dimensionless numbers (see above). Free convection then acting as a local stirring effect assists to produce denser electrodeposits [17]. Accordingly, both surface diffusion and free convection promote correlation effects at protrusions and the development of a fractal surface.

Conversely, for open branched patterns, $L>\delta_{\mathrm{d}}$ and $L^{\prime}>\delta_{\mathrm{d}}$, as each protrusion will tend to grow separately, and the mass transfer boundary layer will tend to follow the surface contour of the protrusion. The tip growth probability is then largely increased. Recently, it has been established [33] that the smallest value of $\delta_{\mathrm{d}}$ at the tip site itself remains constant either for stable or marginally stable tips. In this case, as there is no significant convective contribution at the tip, the rate of mass transfer is mainly determined by the hemispherical diffusion of reactants to the tip surface [34]. Accordingly, the compensation between the high current density at tips and surface relaxation processes, such as that produced by surface adatom diffusion and surface tension effects $[1,2,3]$, determines the tip stability. Then, an optimal tip radius is maintained at a maximum growth rate of the deposit [33]. In contrast to dense branching, for non-correlated open branching the value of $L^{\prime}$ increases along the radial growth of the deposit, turning the current distribution increasingly inhomogeneous. This situation favours the development of open mass fractal domains (Fig. 5c). 


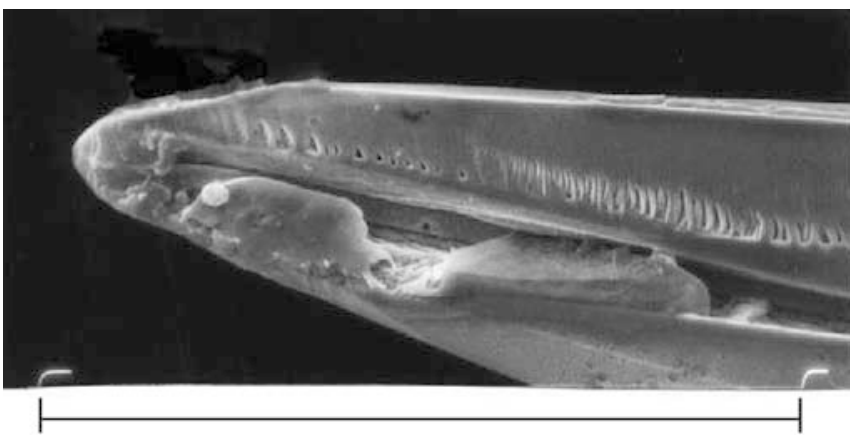

Fig. 9 SEM micrograph of a needle tip. Reference bar $100 \mu \mathrm{m}$

On the other hand, for dendrites, adatom surface diffusion contributes to both branching thickening and to tip stabilization. Growth patterns depicted in Fig. 6 show a slow uniform branch thickening, although the rate of this process appears to be specific to each branch. Thickening also occurs at the tip of dead branches, leading to a compact quasi-spherical deposit. Silver atom surface diffusion also plays a key role in branch thickening, as in the case of metal dendrite formation $[20,35,36]$.

In summary, the growth mode of silver branched electrodeposits in a quasi-2D cell can be described by a complex process involving a competition between phenomena at the macro- and microscopic level promoting the formation of either a compact pattern or irregular patterns, including open and dense branching. The relative contribution of these phenomena depends on $c_{0}$, $\Delta \mathrm{E}_{\mathrm{c}}$ and $t$. Correspondingly, current macro- and microdistributions determine the type of growth mode of the global electrodeposit.

\section{Conclusions}

1. The electrodeposition of silver from silver sulfate aqueous solutions in a quasi-2D cell, at $298 \mathrm{~K}$, produces complex growth patterns involving dense branching, DLA-type, dendrite and needle-like patterns.

2. The dominant morphology depends on $c_{0}, \Delta E_{\mathrm{c}}$ and $t$. Under certain conditions the patterns exhibit domains with different morphologies that are irregularly distributed.

3. The analysis of dimensionless numbers allowed us to distinguish the ionic mass-transfer mechanism contribution in the electrochemical process.

4. The axial-to-radial growth rate ratio of a single branch is close to $10^{2}$.

5. The branch density number increases with $\Delta E_{\mathrm{c}}$ and decreases slightly with $c_{0}$.

6. The formation of complicated silver patterns can be described by a complex physical mechanism involving a competition between phenomena at the macroscopic and atomic level promoting the formation of compact or irregular either open or dense branched patterns.

Acknowledgements This work was financially supported by PIP 4376 and PIP 0897 from Consejo Nacional de Investigaciones Científicas y Técnicas (CONICET) and PICT 97-1993 and PICT 06-03251 from Agencia Nacional de Promoción Científica y Tecnológica of Argentina.

\section{References}

1. Meakin P (1990) In: Avnir D (ed) The fractal approach to heterogeneous chemistry, surfaces, colloids and polymers. Wiley, Chichester, p 131

2. Godrèche C (ed) (1992) Solids far from equilibrium. Cambridge University Press, Cambridge

3. Barabasi AL, Stanley HE (1995) Fractal concepts in surface growth. Cambridge University Press, Cambridge

4. Matsushita M, Hayakawa Y, Honjo H, Sawada Y (1984) Phys Rev Lett 53:286

5. Matsushita M, Hayakawa Y, Sawada Y (1985) Phys Rev A 32:3814

6. Grier DG, Ben-Jacob E, Clarke R, Sanders LM (1986) Phys Rev Lett 56:1264

7. Sawada Y, Dougherty A, Gollub JP (1986) Phys Rev Lett 56:1260

8. Grier SDG, Kessler DA, Sander LM (1987) Phys Rev Lett 59:2315

9. Argoul F, Arneodo A, Grasseau G, Swinney HL (1988) Phys Rev A 61:2558

10. Argoul F, Arneodo A, Elezgaray J, Grasseau G, Murenzi R (1990) Phys Rev A 41:5537

11. Schilardi P, Marchiano SL, Salvarezza RC, Hernández Creus A, Arvia AJ (1997) J Electroanal Chem 431:81

12. Hernández Creus A, Carro P, González S, Salvarezza RC, Arvia AJ (1992) Electrochim Acta 37:2215

13. Hernández Creus A, Carro P, González S, Salvarezza RC, Arvia AJ (1992) J Electrochem Soc 139:1064

14. Carro P, Marchiano SL, Hernández Creus A, González S, Salvarezza RC, Arvia AJ (1993) Phys Rev E 48:R2374

15. Hernández Creus A, Carro P, González S, Marchiano S, Salvarezza RC, Arvia AJ (1994) Fractals Nat Appl Sci A 41:191

16. Guzman MA, Feimuth RD, Prendse PU, Veindt MC, Lam L (1990) In: Lam L, Morris HC (eds) Nonlinear structures in physical systems. Springer, Berlin Heidelberg New York

17. Trigueros PP, Claret J, Mas F, Sagués F (1991) J Electroanal Chem 312:219

18. Kuhn A, Argoul F (1995) J Electroanal Chem 397:93

19. Carro P, Ambrosolio S, Marchiano SL, Hernández Creus A, Salvarezza RC, Arvia AJ (1995) J Electroanal Chem 396:183

20. Martín H, Carro P, Hernández Creus A, González S, Salvarezza RC, Arvia AJ (1997) Langmuir 13:100

21. Bockris JO'M, Reddy AKN (1970) Modern electrochemistry, vol. 2. Macdonald, London, p 125

22. Gerischer H, Tischer RP (1957) Z Elektrochem 61:1159

23. Budevski E, Bostanov W, Vitanov T, Stoinov Z, Kotzewa A, Kaischev R (1966) Electrochim Acta 11:1697

24. Budevski E, Bostanov W, Vitanov T, Stoinov Z, Kotzewa A, Kaischev R (1966) Phys Status Solidi 13:577

25. Porter JD, Robinson TO (1993) J Phys Chem 97:6696

26. Levich B (1962) Physico-chemical hydrodynamics. PrenticeHall, Englewood Cliffs, NJ

27. Newman JS (1991) Electrochemical systems, 2nd edn. PrenticeHall, Englewood Cliffs, N J

28. Ibl N, Dossenbach O (1983) In: Yeager E, Bockris JO'M, Conway BE, Sarangapani R (eds) Comprehensive treatise of electrochemistry, vol. 6. Plenum Press, New York, p 133 
29. Wilke CR, Tobias CW, Eisenberg M (1953) Chem Eng Prog 49:663

30. Meakin P (1998) Fractals, scaling and growth far from equilibrium. Cambridge University Press, Cambridge, p 369

31. Pasquale MA, Marchiano SL, Arvia AJ (2003) J Appl Electrochem (in press)

32. Pasquale MA, Marchiano SL, Arvia AJ (2002) J Electroanal Chem 532:255

33. Pasquale MA, Marchiano SL, Schilardi PL, Salvarezza RC, Arvia AJ (2002) Phys Rev E 65:041608
34. Hwang RQ, Schroeder J, Günter G, Behm RJ (1991) Phys Rev Lett 67:3279

35. Martin H, Carro P, Hernández Creus A, González S, Andreasen G, Salvarezza RC, Arvia AJ (2000) Langmuir 16:2915

36. Gimeno Y, Hernández Creus A, Carro P, González S, Salvarezza RC, Arvia AJ (2002) J Phys Chem B 106:4232 